NEUROGASTROENTEROLOGY

\title{
Treatment of non-cardiac chest pain: a controlled trial of hypnotherapy
}

\author{
H Jones, P Cooper, V Miller, N Brooks, P J Whorwell
}

See end of article for authors' affiliations

Correspondence to: Professor P J Whorwell Education and Research Centre, Wythenshawe Hospital, Southmoor Rd, Wythenshawe,

Manchester M23 9LT, UK;

Peter.Whorwell@

smuht.nwest.nhs.uk

Revised version received 10 March 2006

Accepted for publication

16 March 2006

Published online first

20 April 2006
Background: Non-cardiac chest pain (NCCP) is an extremely debilitating condition of uncertain origin which is difficult to treat and consequently has a high psychological morbidity. Hypnotherapy has been shown to be effective in related conditions such as irritable bowel syndrome where its beneficial effects are long lasting.

Aims: This study aimed to assess the efficacy of hypnotherapy in a selected group of patients with anginalike chest pain in whom coronary angiography was normal and oesophageal reflux was not contributory. Patients and methods: Twenty eight patients fulfilling the entry criteria were randomised to receive, after a four week baseline period, either 12 sessions of hypnotherapy or supportive therapy plus placebo medication over a 17 week period. The primary outcome measure was global assessment of chest pain improvement. Secondary variables were a change in scores for quality of life, pain severity, pain frequency, anxiety, and depression, as well as any alteration in the use of medication.

Results: Twelve of $15(80 \%)$ hypnotherapy patients compared with three of $13(23 \%)$ controls experienced a global improvement in pain $(p=0.008)$ which was associated with a significantly greater reduction in pain intensity $(p=0.046)$ although not frequency. Hypnotherapy also resulted in a significantly greater improvement in overall well being in addition to a reduction in medication usage. There were no differences favouring hypnotherapy with respect to anxiety or depression scores.

Conclusion: Hypnotherapy appears to have use in this highly selected group of NCCP patients and warrants further assessment in the broader context of this disorder.
B etween $10 \%$ and $30 \%$ of patients undergoing coronary angiography for angina-like chest pain are found to have normal coronary arteries ${ }^{1}$ and many continue to be incapacitated by their symptoms despite reassurance that there is no evidence of significant heart disease. These patients with non-cardiac chest pain (NCCP) are particularly hard to manage, firstly, because the cause of their pain is poorly understood and secondly, the condition is notoriously unsatisfactory to treat. As a consequence, they place a large burden on health care resources and it has been estimated that this problem costs the US economy many billions of dollars per year. ${ }^{2}$

A variety of factors have been implicated in the pathogenesis of NCCP, including oesophageal reflux, oesophageal motor dysfunction, ${ }^{4}$ visceral hypersensitivity, ${ }^{5}$ musculoskeletal problems, ${ }^{6}$ and psychological factors. ${ }^{7}$ To complicate matters further, there is some evidence to suggest that even when the coronary arteries are angiographically normal, there may be abnormalities of either coronary flow or the microvascular circulation. ${ }^{8}$ There is even data indicating that infusion of acid into the oesophagus can reduce coronary blood flow, at least in subjects with coronary artery disease. ${ }^{9}$ In addition, it seems reasonable to assume that none of these mechanisms are mutually exclusive and thus they may act in combination to lead to symptoms.

The correlation between manometric events as well as other tests of oesophageal function and symptoms is variable ${ }^{10-12}$ although probably the most consistent association is with oesophageal reflux. ${ }^{13}{ }^{14}$ Clinical trials of proton pump inhibitors have shown a positive effect ${ }^{15}$ and it has even been suggested that administration of such a medication could be used as a diagnostic test ${ }^{16-18}$ for confirming the role of reflux in the symptoms of a particular individual. As a consequence, these agents are frequently used as firstline treatment, even in the absence of reflux symptoms, and in this situation it is often recommended that they are prescribed at high dose. ${ }^{19}$ The only other pharmacological approach that is supported by reasonable evidence is the use of tricyclic antidepressants $^{2021}$ and possibly selective serotonin reuptake inhibitors. $^{22}$ These are always worth trying although tricyclic antidepressants are associated with a high rate of side effects. ${ }^{23}$ Calcium antagonists have been shown to reduce oesophageal motility ${ }^{24}$ and are frequently used, although in clinical practice as well as trials their effects have been disappointing. ${ }^{11}{ }^{25}$ Despite the use of these pharmacological approaches, many patients remain symptomatic and there is a strong need for new treatment approaches.

The biopsychosocial model of disease ${ }^{15}$ as it relates to gastrointestinal illness ${ }^{26}$ is particularly applicable to NCCP and it might therefore be anticipated that educative and behavioural techniques for treating this condition might be rewarding. However, there have been relatively few trials of this type and those that have been undertaken have mainly involved cognitive behavioural-type approaches ${ }^{27-30}$ and the results have been encouraging.

We have previously shown that functional gastrointestinal disorders such as irritable bowel syndrome (IBS) ${ }^{3132}$ and functional dyspepsia ${ }^{33}$ appear to respond extremely well to hypnotherapy with the beneficial effects being sustained over time. ${ }^{34}$ As NCCP is also classed as a functional gastrointestinal disorder, it was the purpose of this study to assess the efficacy of hypnotherapy in a selected group of patients with angina-like chest pain in whom coronary angiography was normal and oesophageal reflux did not appear to be contributing to the problem.

Abbreviations: NCCP, non-cardiac chest pain; IBS, irritable bowel syndrome; $Q O L$, quality of life; HAD, hospital anxiety depression 


\section{METHODS}

\section{Patient selection}

Patients attending the regional cardiothoracic centre for investigation of angina-like chest pain in whom coronary angiography was normal were eligible to be considered for the study. In order to be suitable for randomisation they needed to be able to attend the department over a period of at least 17 weeks, have no coexistent disease, and experience chest pain at least once a week. The contribution of oesophageal reflux to their problem was excluded in all patients by 24 hour $\mathrm{pH}$ monitoring. If patients had taken a proton pump inhibitor it was necessary for them not to have responded to this medication. Similarly, if gastroscopy had been undertaken as part of the initial workup, it had to be normal. Patients were allowed to continue with their current medications as long as they had been taking them for three months at a constant dose. As part of their informed consent, patients were told they would receive either hypnotherapy or supportive listening plus a medication that might improve their symptoms.

\section{Study design}

The study was a single (investigator) blind randomised parallel design where patients were allocated to receive either hypnotherapy or supportive listening plus placebo medication which was supplied by Janssen Pharmaceuticals in the form of a round white tablet that did not resemble any of the antisecretory medications on the market which the patient could have previously taken. Following randomisation using a computer generated randomisation list, symptoms were recorded for a one month baseline period before treatment started. Treatment was administered over a 17 week period, with patients attending for 30 minute sessions for nine weeks, followed by fortnightly visits for four weeks, and a final visit after a further four weeks. Efficacy of treatment was assessed by comparing scores at the beginning and end of the treatment periods ( 17 weeks). Supportive listening and hypnotherapy were both delivered in a single room in the hypnotherapy unit over exactly the same time period and each session lasted the same length of time. Thus the two treatments were designed to mimic each other except for the use of hypnotherapy.

\section{Interventions}

\section{Hypnotherapy}

This was undertaken by a therapist, who was not a physician, in a similar manner to our previous trials, and has been described in detail elsewhere. ${ }^{35}{ }^{36}$ Patients were initially given a tutorial about their condition and the factors that may be involved, such as disturbances of motility, visceral sensation in conjunction with stress, and how all this might be modified by hypnosis. Hypnosis was induced by eye closure, followed by progressive muscular relaxation and standard deepening techniques. For the first two sessions this process was repeated to familiarise the patient with the process. Subsequently, "chest focused" suggestions were introduced, centred around normalisation of function of oesophageal motility and sensitivity using both imagery and conditioning techniques. More direct suggestions about reduction of pain and improvement of health were made on a repetitive basis at each session. Subjects were also given an audio tape or CD of a session and encouraged to practise at home on at least a daily basis.

\section{Supportive therapy}

This was undertaken by a research assistant, of equal status to the hypnotherapist (that is, not counsellor versus medical practitioner), who had been trained to provide counselling and support. Patients were encouraged to talk about their physical symptoms as well as any emotional issues and to discuss how these might be coped with in a better way. In addition, as with our previous trials, patients were also given a placebo medication. The placebo served two purposes: firstly, to boost the effect of the control treatment as much as possible as well as improving expectation, and secondly, to ensure that the control patients returned regularly to collect their medication. This latter aspect was important, especially if patients were not responding well to the supportive listening. Medication was not given to the hypnotherapy patients as it would not have been appropriate to boost this form of treatment in any way. Furthermore, had a placebo been added to the hypnotherapy arm it would have been difficult to decide whether it was the hypnotherapy or the placebo that had accounted for any observed benefit. No attempt was made to offer any form of relaxation techniques to the control patients.

\section{End points}

All outcome data comparing status at baseline and the end of the treatment period were collected and subsequently analysed by an independent researcher who was not involved in any of the treatments and was kept completely blind to the treatment allocation of all patients throughout the course of the study.

\section{Primary end point}

It is currently recommended that the primary end point in therapeutic trials in functional disorders should be some form of global assessment. ${ }^{37}$ Therefore, the primary end point for this trial was a global assessment of chest pain. Patients were therefore asked at the end of the treatment period, "compared with how the chest pain was before starting treatment, how would you rate the problem now? Completely better, moderately better, slightly better, no change, slightly worse, moderately worse, much worse". Patients responding as either completely better or moderately better were regarded as improved.

\section{Secondary end points}

(1) Quality of life (QOL): in the absence of a specific QOL instrument for NCCP, we used a global assessment of well being as a measure of this aspect of the patient's problem. For global well being the patient was asked, "compared with how you generally felt before treatment, how do you rate how you feel now? Completely better, moderately better, slightly better, no change, slightly worse, moderately worse, much worse." Those responding as either completely better or moderately better were regarded as improved. In addition, the MacNew ${ }^{38}{ }^{39} \mathrm{QOL}$ instrument, developed for patients with proven heart disease, was also used. This contains 27 questions, all recorded on a $0-7$ scale, divided into three domains, emotional, physical, and social, which are totalled to give a final score. Final scores covering baseline and the last four weeks of treatment were compared with an increase in score indicating an improvement.

(2) Pain severity: patients were asked to rate their pain severity during the four week baseline and the last four weeks of treatment on a linear analogue scale from 0 100, similar to that used in our IBS severity scoring system..$^{40}$ A reduction in pain score in excess of 10 was regarded as clinically significant.

(3) Frequency of pain: patients were asked to report the number of pain episodes per month during the four week baseline and the last four weeks of treatment.

(4) Hospital anxiety depression (HAD) scale ${ }^{41}$ : this is a short questionnaire containing seven anxiety and seven 


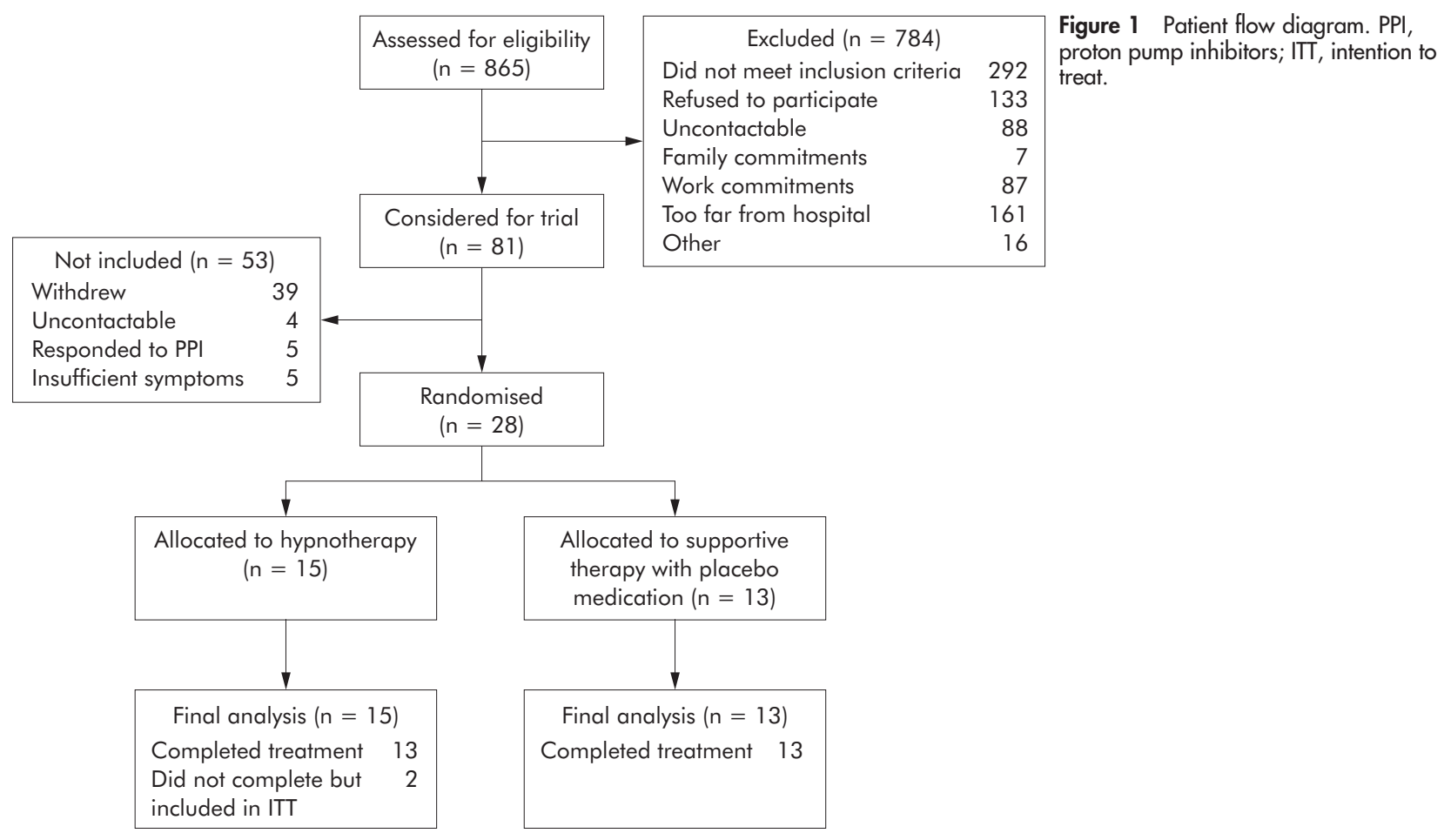

depression items. A score between 0 and 21 is obtained for either domain, with a value of 10 or over indicating clinically significant anxiety or depression.

(5) Medication usage: we adopted a pragmatic approach to concomitant medication as patients with NCCP are often reluctant to come off any medication for their condition, even if it is not especially effective. Thus medication was allowed on entry to the trial and it was acceptable for it to be reduced or added to at the discretion of their general practitioner. It was considered that any change in medication needs could be regarded as a secondary end point.

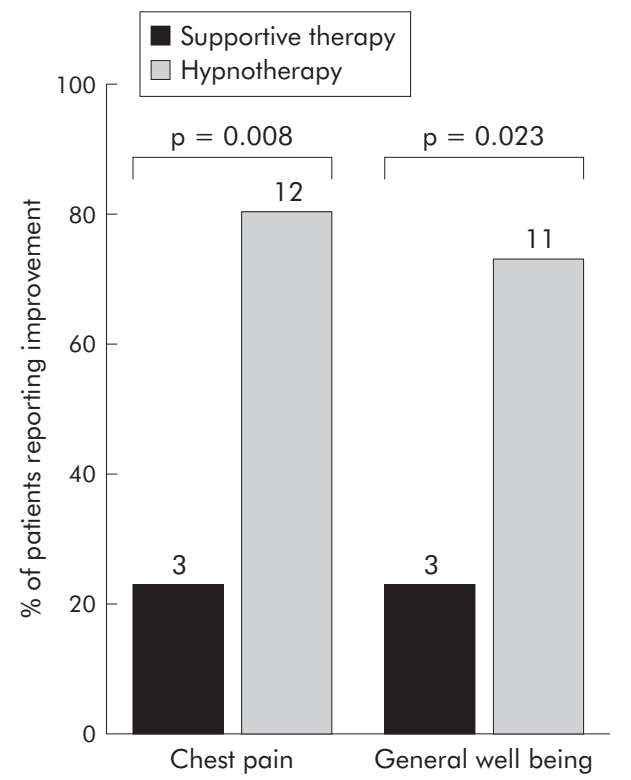

Figure 2 Percentage of patients reporting a global improvement in chest pain or general well being with either hypnotherapy $(n=15)$ or supportive therapy $(n=13)$.

\section{Statistics}

Comparisons between the two groups were made using the $\chi^{2}$ test, two sample $t$ tests, and the Mann-Whitney $U$ test as appropriate, using the conventional two sided 5\% significance level.

Analysis of covariance and multiple logistic regression were undertaken assessing the effect of age, anxiety, and any other potential confounding factors on the statistical significance of the effect of hypnotherapy on any of the outcomes.

\section{RESULTS}

Figure 1 documents the flow of patients through the study, leading to 28 patients eventually being recruited and randomised. The main reasons for patients not being recruitable were oesophageal reflux disease, coexistent disease, patients living too far from the hospital, and unwillingness to participate in the study. Of the 28 patients recruited to the study, 15 (mean age 60 years, 10 females) were randomised to hypnotherapy and 13 (mean age 54 years, eight females) to supportive listening plus placebo. Two patients in the hypnotherapy group failed to complete the course of treatment so the last results for these individuals were used in the intent to treat analysis.

Figure 2 documents the primary outcome measure of global assessment of chest pain as well as the secondary end point of global assessment of well being (QOL). It is clear that $80 \%$ of the hypnotherapy group were improved with regard to chest pain compared with only $23 \%$ of controls $(p=0.008)$. Global assessment of general well being (QOL) was also improved in $73 \%$ of hypnotherapy patients compared with $23 \%$ of controls $(p=0.023)$. There was a slight imbalance between the two groups in terms of age and HAD anxiety. Adjusting these two outcomes for age and HAD anxiety marginally changed the significance of the effect of hypnotherapy to $p=0.0017$ for pain and $p=0.036$ for general well being (QOL).

Table 1 documents pain severity, pain frequency, anxiety scores, depression scores, total MacNew scores, and medication usage. As can be seen, there was a significantly greater 
Table 1 Effect of hypnotherapy and control therapy on pain, anxiety, depression, and MacNew scores as well as medication use

\begin{tabular}{|c|c|c|c|c|c|c|c|}
\hline & \multicolumn{3}{|c|}{ Supportive therapy $(n=13)$} & \multicolumn{3}{|c|}{ Hypnotherapy ( $n=15$ ) } & \multirow{2}{*}{$\begin{array}{l}\text { Significance } \\
\text { between } \\
\text { groups }\end{array}$} \\
\hline & Baseline & $\begin{array}{l}\text { End of } \\
\text { treatment }\end{array}$ & Change & Baseline & $\begin{array}{l}\text { End of } \\
\text { treatment }\end{array}$ & Change & \\
\hline Change $^{*}$ in pain scores & $60.62(17.9)$ & $47.31(26.55)$ & $13.31(18.44)$ & $59.7(18.66)$ & $29.13(25.31)$ & $30.53(24.19)$ & 0.046 \\
\hline Change $^{*}$ in pain frequency scores & $28(4,28)$ & $20(4,28)$ & $0(-8,22)$ & $24(2,28)$ & $12(0,28)$ & $8(-8,25)$ & 0.20 \\
\hline Change $^{*}$ in anxiety scores & $4(3,13)$ & $5(0,19)$ & $-1(-4,15)$ & $6(4,15)$ & $7(2,13)$ & $0(-4,4)$ & 0.56 \\
\hline Change $^{*}$ in depression scores & $5(1,13)$ & $5(1,14)$ & $-1(-5,10)$ & $5(1,10)$ & $5(1,11)$ & $0(-3,9)$ & 0.47 \\
\hline Change $^{\star *}$ in total MacNew score & $4.63(0.96)$ & 4.68 (1.07) & $0.05(0.35)$ & $4.82(0.91)$ & $5.16(0.81)$ & $0.34(0.45)$ & 0.07 \\
\hline Change $^{*}$ in number of medications & $1(0,6)$ & $1(0,6)$ & $0(-2,3)$ & $2(0,4)$ & $0(0,4)$ & $-1(-3,0)$ & 0.017 \\
\hline
\end{tabular}

reduction in pain severity in the hypnotherapy group compared with those receiving supportive listening plus placebo medication $(\mathrm{p}=0.046)$. Adjusting the pain scores for the effect of age and baseline anxiety score marginally increased the significance of the effect of hypnotherapy $(p=0.032)$. There was a reduction in pain frequency in favour of hypnotherapy but this did not reach significance. There was also some evidence that the hypnotherapy group showed a higher degree of improvement in total MacNew scores $(p=0.07)$. There were no significant differences between treatment groups in terms of improvement in anxiety or depression.

Some patients in both groups were taking beta blockers, calcium channel blockers, potassium channel activators, nitrates, aspirin, and statins. With the exception of statins, which were more commonly taken by controls, the distribution of these classes of drug was equal between the two groups. Hypnotherapy patients were able to reduce their medication usage whereas this increased in controls, creating a significant difference in favour of hypnotherapy $(\mathrm{p}=0.017)$.

\section{DISCUSSION}

The fact that such clearcut differences in the chest pain primary outcome favouring hypnotherapy emerged in this trial, despite the relatively small size of the sample, indicates that this form of treatment could have considerable potential in NCCP. In addition, QOL, in terms of general well being, also significantly improved. MacNew QOL scores did not quite reach significance but it has to be borne in mind that this instrument is designed to assess QOL in individuals with proven heart disease and therefore might not be as sensitive in NCCP.

There is good evidence to suggest that patients with NCCP and normal coronary arteries have an excellent prognosis in terms of life expectancy ${ }^{42}$ and that the risk of developing coronary artery disease at a later date is remarkably low. ${ }^{43}$ Despite this, these patients remain difficult to reassure, presumably because of the cardiac connotations of their symptoms, and this adds another dimension to NCCP which is not apparent in other functional gastrointestinal disorders. Consequently, patients with NCCP often continue to take their antiangina medications, which was certainly observed in this study, and even their medical attendants are sometimes reluctant to stop them in case there is an element of undetected coronary artery disease or spasm. They also continue to seek medical advice ${ }^{44}$ and it has been shown that they consult even more than individuals with demonstrable coronary artery disease. As a consequence, there has been a considerable focus on the psychological components of NCCP with a variety of models being suggested on how to care for these individuals. ${ }^{35-47}$ It is therefore somewhat surprising that there have been relatively few trials of behavioural interventions compared with the large numbers that have been undertaken in other functional conditions, such as IBS. The main focus with respect to these approaches in NCCP has been on cognitive behavioural therapy, although this form of treatment has usually been compared with normal care rather than controlling for the increased attention associated with these forms of treatment. In this study, rather than comparing with usual care, we controlled for the attention of hypnotherapy by having a comparator group exposed to a therapist for the same length of time as the hypnotherapy group. Furthermore, a placebo medication was also given to controls in an attempt to maximise the expectation of beneficial effects of their treatment.

This study concentrated on a small well defined subgroup of patients with NCCP who had normal coronary angiography and no evidence of reflux associated chest pain. However, many patients with angina-like chest pain and no response to proton pump inhibitors have a completely normal exercise ECG and are therefore not subjected to coronary angiography, particularly if they are relatively young and have no other risk factors. Similarly, they are not routinely subjected to investigation of oesophageal motility or sensitivity as it is felt by some that the correlation with symptoms is not especially good ${ }^{10-12}$ and that the available pharmacological approaches are not sufficiently sophisticated to target such abnormalities, even if they are identified.

We have previously shown that hypnotherapy can lead to normalisation of visceral sensation in the gut ${ }^{48}$ as well as reducing the contractile activity of the distal colon. ${ }^{49}$ Furthermore, this form of treatment undoubtedly leads to a reduction in stress and helps to improve the negative cognitions associated with functional gastrointestinal disorders. $^{50}$ There is also clinical evidence that it has good pain relieving qualities and this may be explained in part by brain imaging studies which have shown an effect on the anterior singulate cortex, a region of the brain where the emotional content of a painful stimulus is processed. ${ }^{51}$ In addition, it has been shown that hypnosis can reduce gastric acid secretion, and before the recognition of the role of Helicobacter pylori in peptic ulcer disease, it was shown to be useful in maintaining remission in that condition. ${ }^{52}$ Thus it is clear that hypnosis has the potential to influence many of the mechanisms that have been implicated in the pathogenesis of NCCP. Therefore, it seems reasonable to speculate that this form of treatment could be useful in all forms of NCCP, irrespective of cause, and might even be useful in those with acid reflux.

One of the drawbacks of hypnotherapy is that it is labour intensive for both patient and therapist, with the latter making it rather expensive to provide. However, if the beneficial effects are sustained, then substantial savings are likely because of the high costs of these patients in terms of 
continuing consultation, medication, and repetitive investigation. We have previously found that IBS patients treated with hypnotherapy do remain well in the long term, with $83 \%$ of initial responders continuing to do well up to and in excess of five years following treatment with dramatically reduced medication needs and consultation rates. ${ }^{34}$ In addition, these individuals take far less time off work or, if permanently off work, are able to resume employment. It therefore seems reasonable to assume that similar long term benefits should be forthcoming in NCCP, especially as we noted a significant reduction in medication needs, even in the short term.

There are some limitations to this study which need to be highlighted. Unfortunately, it is impossible to undertake a double blind trial of treatments such as hypnotherapy because it is inevitable that the recipient will know what form of treatment they are receiving. However, this should not be allowed to become a bar to attempting trials of potentially useful treatment modalities such as hypnosis, as otherwise they would never become adequately evaluated. We therefore employed a single blind trial design that we have successfully used in the past and which has proved extremely robust. ${ }^{3133}$ This involves having all outcomes assessed by an investigator completely independent of the therapists and kept blind to the treatment allocation. In addition, a medication placebo is also administered to the control group in order to augment the response to treatment in this group and therefore provide as effective a comparator for hypnotherapy as is possible. It is possible that patients may be disappointed at the prospect of not receiving hypnotherapy and that expectation, which was not recorded in this study, might not be as high in the control group. However, it is noteworthy that the patients in this study were not aware of our previous work on the use of hypnotherapy in IBS and functional dyspepsia, presumably because they had received most of their management in the cardiological setting. As a result, they were surprisingly sceptical of the prospect of hypnosis helping them with their problem to the extent that this even adversely affected recruitment. This group of patients seemed to be particularly focused on a pharmacological approach to their disorder much more than is usually seen in other functional gastrointestinal disorders. Thus provision of a "medication" in the control group probably served its purpose well by considerably boosting expectation in these individuals. It might also be argued that the response rate in the control group was rather low, thus artificially inflating the significance of the results. However, it should be noted that the criterion for response, which excluded individuals who showed a slight improvement, was much stricter in this study than that often used in functional gastrointestinal trials where an "adequate" response is often judged acceptable..$^{53}$ Thus it might be predicted that a lower response rate in the controls would be observed in this trial.

The results of this study, undertaken on a highly selected group of patients, indicate that hypnotherapy could have considerable potential in the wider context of NCCP, especially as its beneficial effects in other functional disorders have been shown to be sustained..$^{34}$ Thus further research is probably now justified although the design of any future trials would need to be different. Recruitment to the current study was severely limited by the necessity for extensive negative investigation, absence of coexistent disease, and the requirement for the contribution of oesophageal reflux to be excluded. It was necessary for all patients to have had coronary angiography which meant that they were more likely to be older and have other reasons for investigation resulting in them being less likely to be eligible for the study. Any future trials should probably be of a more pragmatic design, possibly having a negative exercise ECG and failure to respond to a proton pump inhibitor as the entry criteria. This is important because many sufferers are often relatively young, female, have no significant risk factors, and therefore do not justify coronary angiography. Despite this, their burden on healthcare resources is still considerable and if hypnotherapy was successful in this situation it might prevent much suffering. In addition, it may avoid the necessity for coronary angiography, which is sometimes undertaken largely for the purpose of reassurance.

\section{ACKNOWLEDGEMENTS}

This study was supported by a grant from the NHS Executive North West Biomedical Funding Scheme.

We are grateful to Dr Julie Morris, senior medical statistician, for advice regarding analysis of the data and to the cardiologists from the Wythenshawe Hospital Cardiothoracic Centre for giving us access to their patients.

\section{Authors' affiliations}

H Jones, P Cooper, V Miller, N Brooks, P J Whorwell, Departments of Medicine and Cardiology, Wythenshawe Hospital, Manchester, UK

Conflict of interest: None declared.

\section{REFERENCES}

1 Chambers JB, Bass C. Chest pain with normal coronary anatomy: a review of natural history and possible etiologic factors. Prog Cardiovasc Dis 1990:33:161-84

2 Eslick GD Coulshed DS, Talley NJ. Review article: the burden of illness of non cardiac chest pain. Aliment Pharmacol Ther 2002;16:1217-23.

3 Esler JL, Bock BC. Psychological treatments for non cardiac chest pain: recommendations for a new approach. J Psychosom Res 2004;56:263-9.

4 Benjamin SB, Gerhardt CD, Castell DO. High amplitude peristaltic contractions associated with chest pain and/or dysphagia. Gastroenterology 1979;77:478-83.

5 Richter JE, Barish CF, Castell DO. Abnormal sensory perception in patients with esophageal chest pain. Gastroenterology 1986;91:845-52.

6 Epstein SE, Gerber LH, Borer JS. Chest wall syndrome: a common cause of unexplained cardiac pain. J Am Med Assoc 1979;241:2793-7.

7 Ho KY, Kang JY, Yeo B, et al. Non cardiac, non-oesophageal chest pain: the relevance of psychological factors. Gut 1998;43:105-10.

8 Cannon RO, Cattau EL, Yakshe PN, et al. Coronary flow reserve, esophageal motility, and chest pain in patients with angiographically normal coronary arteries. Am J Med 1990;88:217-22.

9 Chauhan A, Mullins PA, Taylor G, et al. Cardioesophageal reflex: a mechanism for "linked angina" in patients with angiographically proven coronary artery disease. J Am Coll Cardiol 1996;27:1621-8.

10 Goyal RK. Changing focus on unexplained esophageal chest pain. Ann Intern Med 1996;124:1008-11

11 Botoman VA. Non cardiac chest pain. J Clin Gastroenterol 2002;34:6-14.

12 Heatley M, Rose K, Weston C. The heart and the oesophagus: intimate relations. Postgrad Med J 2005:81:515-18.

13 DeCaestecker JS, Blackwell JN, Brown J, et al. The oesophagus as a cause of recurrent chest pain: which patients should be investigated and which tests should be used? Lancet 1985;2:1143-6.

14 Hewson EG, Sinclair JW, Dalton CB, et al. Twenty-four hour esophageal pH monitoring. The most useful test for evaluating non cardiac chest pain. Am J Med 1991;90:576-83.

15 Achem SR, Kolts BE, MacMath T, et al. Effects of omeprazole versus placebo in treatment of non cardiac chest pain and gastroesophageal reflux. Dig Dis Sci 1997:42:2138-45.

16 Fass R, Fennerty MB, Ofman JJ, et al. The clinical and economic value of a short course of omeprazole in patients with non cardiac chest pain. Gastroenterology 1998;115:42-9.

17 Pandak WM, Arezo S, Everett S, et al. Short course of omeprazole. A better first diagnostic approach to non cardiac chest pain than endoscopy, manometry, or 24-hour esophageal pH monitoring. J Clin Gastroenterol 2002;35:307-14.

18 Richter JE. Cost-effectiveness of testing for gastroesophageal reflux disease: what do patients, physicians, and health insurers want? Am J Med 1999;107:288-9.

19 Bautista J, Fullerton $\mathrm{H}$, Briseno $M$, et al. The effect of an empirical trial of highdose lansoprazole on symptom response of patients with non cardiac chest pain - a randomized, double-blind, placebo-controlled, crossover trial. Aliment Pharmacol Ther 2004;19:1123-30.

20 Prakash C, Clouse RE. Long-term outcome from tricyclic antidepressant treatment of functional chest pain. Dig Dis Sci 1999;44:2373-9.

21 Clouse RE, Lustman PJ, Eckert TC, et al. Low-dose trazodone for symptomatic patients with esophageal contraction abnormalities. A double-blind, placebocontrolled trial. Gastroenterology 1987;92:1027-36.

22 Varia I, Logue E, O'Connor C, et al. Randomized trial of sertraline in patients with unexplained chest pain of non cardiac origin. Am Heart $J$ 2000;140:367-72 
23 Cox ID, Hann CM, Kaski JC. Low dose imipramine improves chest pain but not quality of life in patients with angina and normal coronary angiograms. Eur Heart J 1998; 19:250-4

24 Richter JE, Dalton CB, Buice RG, et al. Nifedipine: a potent inhibitor of contractions in the body of the human esophagus. Studies in healthy volunteers and patients with the nutcracker esophagus. Gastroenterology 1985;89:549-54

25 Richter JE, Dalton CB, Bradley LA, et al. Oral nifedipine in the treatment of non cardiac chest pain in patients with the nutcracker esophagus. Gastroenterology 1987;93:21-8.

26 Drossman DA. Gastrointestinal illness and the biopsychosocial model. J Clin Gastroenterol 1996;22:252-4

27 Klimes I, Mayou RA, Pearce MJ, et al. Psychological treatment for atypical non cardiac chest pain: a controlled evaluation. Psychol Med 1990;20:605-11.

28 Mayou RA, Bryant BM, Sanders D, et al. A controlled trial of cognitive behavioural therapy for non cardiac chest pain. Psychol Med 1997; 27:1021-31.

29 van Peski-Oosterbaan AS, Spinhoven P, van Rood Y, et al. Cognitivebehavioural therapy for non cardiac chest pain: a randomized trial. Am J Med 1999; 106:424-9.

30 Potts SG, Lewin R, Fox KAA, et al. Group psychological treatment for chest pain with normal coronary arteries. Q J Med 1999;92:81-6.

31 Whorwell PJ, Prior A, Faragher EB. Controlled trial of hypnotherapy in the treatment of severe refractory irritable bowel syndrome. Lancet 1984;ii: 1232-4.

32 Gonsalkorale WM, Houghton LA, Whorwell PJ. Hypnotherapy in irritable bowel syndrome: a large-scale audit of a clinical service with examination of factors influencing responsiveness. Am J Gastroenterol 2002;97:954-61.

33 Calvert E, Houghton LA, Cooper $P$, et al. Long-term improvement in functional dyspepsia using hypnotherapy. Gastroenterology 2002;123:1778-85.

34 Gonsalkorale WM, Miller V, Afzal A, et al. Long term benefits of hypnotherapy for irritable bowel syndrome. Gut 2003;52:1623-9.

35 Gonsalkorale WM, Whorwell PJ. Hypnotherapy in the treatment of irritable bowel syndrome. Eur J Gastroenterol Hepatol 2005;17:15-20.

36 Whorwell PJ. The history of hypnotherapy and its role in the irritable bowel syndrome. Aliment Pharmacol Ther 2005;22:1061-7.

37 Veldhuyzen van Zanten SJ, Talley NJ, Bytzer $P$, et al. Design of treatment trials for functional gastrointestinal disorders. Gut 1999:45(suppl 2):1169-77.

38 Valenti L, Lim L, Heller RF, et al. An improved questionnaire for assessing quality of life after acute myocardial infarction. Qual Life Res 1996;5:151-61.
39 Hofer S, Lim L, Guyatt G, et al. The MacNew heart disease health-related quality of life instrument: A summary. Health Qual Life Outcomes 2004;2:3.

40 Francis CY, Morris J, Whorwell PJ. The irritable bowel severity scoring system: a simple method of monitoring irritable bowel syndrome and its progress. Aliment Pharmacol Ther 1997;11:395-402.

41 Zigmond AS, Snaith RP. The hospital anxiety and depression scale. Acta Psychiatr Scand 1983;67:361-70.

42 Prina LD, Decker WW, Weaver AL, et al. Outcome of patients with a final diagnosis of chest pain of undetermined origin admitted under the suspicion of acute coronary syndrome: A report from the Rochester Epidemiology Project. Ann Emerg Med 2004;43:59-67.

43 Marchandise B, Bourassa MG, Chaitman BR, et al. Angiographic evaluation of the natural history of normal coronary arteries and mild coronary atherosclerosis. Am J Cardiol 1978;41:216-20.

44 Eslick GD, Talley NJ. Non cardiac chest pain: predictors of health care seeking, the types of health care professional consulted, work absenteeism and interruption of daily activities. Aliment Pharmacol Ther 2004;20:909-15.

45 Chambers J, Bass C. Atypical chest pain: looking beyond the heart. Q J Med 1998;91:239-44.

46 Mayou RA, Bass CM, Bryant BM. Management of non cardiac chest pain: from research to clinical practice. Heart 1999:81:387-92.

47 Fang J, Bjorkman D. A critical approach to non cardiac chest pain: pathophysiology, diagnosis and treatment. Am J Gastroenterol 2001;96:958-68.

48 Lea R, Houghton LA, Calvert EL, et al. Gut focused hypnotherapy normalises disordered rectal sensitivity in patients with irritable bowel syndrome. Aliment Pharmacol Ther 2003;17:635-42.

49 Whorwell PJ, Houghton LA, Taylor E, et al. Physiological effects of emotion: assessment via hypnosis. Lancet 1992;340:69-72.

50 Gonsalkorale WM, Toner B, Whorwell PJ. Cognitive change in patients undergoing hypnotherapy for irritable bowel syndrome. J Psychosom Res 2004;56:271-8.

51 Rainville $\mathbf{P}$, Duncan $\mathrm{GH}$, Price DD, et al. Pain affect encoded in human anterior cingulate but not somatosensory cortex. Science 1997;277:969-71.

52 Colgan SM, Faragher EB, Whorwell PJ. Controlled trial of hypnotherapy in relapse prevention of duodenal ulceration. Lancet 1988;331:1299-300.

53 Camilleri M, Northcutt AR, Kong S, et al. Efficacy and safety of alosetron in women with irritable bowel syndrome: a randomised, placebo-controlled trial. Lancet 2000;355:1035-40.

\section{EDITOR'S QUIZ: GI SNAPSHOT}

Answer

From question on page 1402

Figure 2 shows columnar epithelium (arrow) which is of the non-mucin secreting type, and in fig 3 the surrounding stroma is positive for $\mathrm{CDI} 0$ (positivity being reflected by the areas of brown staining) consistent with the diagnosis of colonic endometriosis. CD10, a human membrane associated neutral endopeptidase, is widely used in lymphoma phenotyping but it also stains normal, ectopic, and neoplastic endometrial stromal cells. Hence it is used as an adjunctive diagnostic tool in difficult cases of endometriosis.

Endometriosis is a common condition affecting $8-15 \%$ of menstruating women. Colonic involvement is seen in $15-37 \%$ of patients with pelvic endometriosis. Meyer described the first case of colonic endometriosis in 1909 and Bashist et al reported the first colonic endometriosis confirmed on endoscopic biopsy in 1983.

The intestinal tract is the most common site for extra-genital endometriosis. Other sites include the urinary tract, surgical scars, skin, umbilicus, lung, diaphragm, liver, and pancreas. The rectosigmoid area is the most affected part of the intestinal tract followed by the small intestine, caecum, and appendix. Although most of the patients can be asymptomatic, they can present with cyclical haematochezia, altered bowel habit, abdominal pain, intestinal obstruction, and abdominal mass. As most endometrial deposits are in the serosa, muscularis propria, and submucosa, colonoscopy can be negative. Due to the localising and stricturing nature, it can mimic Crohn's disease and malignancy creating a diagnostic difficulty. Ultrasound and magnetic resonance imaging are useful in diagnosing endometriosis depending on its size and location. Laparoscopy is the preferred investigation as it allows complete evaluation of both intestinal and genital tracts.

Treatment depends on the patient's age, desire for pregnancy, and severity of the condition. Medical therapy with hormonal manipulation to inhibit endometrial growth is usually ineffective in colonic disease. Surgical options are laser therapy for serosal implants and laparoscopic or open resection of the affected bowel segment with or without removal of the uterus and ovaries. 